\title{
UJI KETERGUNAAN LAYANAN ANTARMUKA MAGISTER MANAGEMENT DIGITAL LIBRARY (MM-DIGILIB) PERPUSTAKAAN MAGISTER MANAJEMEN FAKULTAS EEKONOMI UNIVERSITAS INDONESIA
}

\author{
Sri Sugianti \\ Perpustakaan Balai Penelitian Kehutanan Banjarbaru - Kemenhut
}

\begin{abstract}
A digital library is an advancement of a conventional library. Wider role of a digital library lies in its ability to give support for service via virtual/electronic/digital network. Through its revolutionary presence, a digital library needs a test for development. One of the tests that can be used is usage test of interface service of magister management Digital Library (MM-Digilib) at Magister Management of Faculty of Economics, University of Indonesia. Based on the formula of Slovin and Nomogram Henry King, there are 81 valid samples out of 651 of master students accessing digital theses at Magister Management Library, Faculty of Economics, University of Indonesia. Out of indicators of usage testefficiency, effectiveness, ease of use and ease of interaction of MM-Digilib is in general relatively good. Yet it needs to improve the function of Advanced Search in order to assist and shorten time in searching.
\end{abstract}

Keywords: Digital Library, Test Interoperability, MM-Dissertations Interface; Library Management Master FE-UI

Abstrak

Perpustakaan digital sebagai pengembangan dari bentuk perpustakaan tradisional. Keluasan peran dari perpustakaan digital terletak pada kemampuannya memberikan dukungan pelayanan berupa jaringan informasi secara virtual/eletronik/digital. Dalam kehadirannya yang begitu revolusioner, perpustakaan memerlukan suatu pengembangan melalui pengujian. Salah satu pengujian yang bisa dilakukan adalah Uji Ketergunaan Layanan Antarmuka Magister Management Digital Library (MMDigilib) pada Perpustakaan Magister Manajemen FE-UI. Berdasarkan rumus Slovin dan Nomogram Herry KING, diambil 81 sampel yang valid dari keseluruhan populasi 651 orang mahasiswa S2 yang mengakses tesis digital di Perpustakaan Magister Manajemen FE-UI. Dari uji ketergunaan indikatorindikator Segi Efisiensi, Segi Efektifitas, Kemudahan Mempelajari dan Kemudahan Interaksi menunjukkan bahwa Magister Mangement Digital Library (MM-Digilib) secara umum sudah cukup baik. Hanya perlu meningkatkan fungsi Advanced Search agar lebih memudahkan dan mempersingkat waktu dalam penelusuran.

Kata Kunci : Perpustakaan Digital ; Uji Ketergunaan ; Antarmuka MM-Digilib ; Perpustakaan Magister Manajemen FE-UI

\section{PENDAHULUAN}

Perpustakaan dalam fungsinya mengemban amanat sebagai sarana edukasi, rekreasi, dan pusat informasi serta pusat pembelajaran memainkan peran penting dalam membentuk masyarakat yang terpelajar dan maju.

Seiring perkembangan teknologi yang melahirkan berbagai inovasi, Perpustakaan Magister Manajemen-FEUI (selanjutnya disebut MM-FE UI) melakukan terobosan dengan menggunakan
Magister Mangement-Digilib (selanjutnya disingkat MM-Digilib) untuk melakukan pelayanan informasi yang berbasis teknologi website untuk membantu pengguna mendapatkan informasi tentang koleksi Perpustakaan MM-FEUI secara lebih mudah dan praktis. MM-Digilib ini merupakan adopsi dari perangkat lunak (software) Ganesha Digital Library (GDL) 4.0. Software modifikasi ini dimanfaatkan oleh pengguna Perpustakaan MMFEUI untuk mendapatkan informasi koleksi secara 
umum baik buku teks terutama koleksi digital perpustakaan seperti jurnal yang dilanggan ataupun majalah yang telah terdigitalisasi secara cepat melalui abstrak dan metadata yang dapat memudahkan pengguna mengakses secara full text bahkan mengunduh koleksi tersebut untuk kepentingan kegiatan belajar.

Hadirnya MM-Digilib ini memungkinkan interaksi yang cukup banyak antara mahasiswa dengan koleksi digital perpustakaan. Untuk mengetahui sejauh mana MM-Digilib telah memenuhi kebutuhan informasi mahasiswa MMFEUI dari segi efisiensi, efektifitas, kepuasan dan kemudahan penggunaan MM-Digilib perlu diadakan uji ketergunaan dengan fokus pada layanan antarmuka MM-Digilib dengan alasan bahwa layanan ini yang menghubungkan pengguna dengan koleksi digital perpustakaan yang tersimpan dan ditampilkan dalam bentuk wakil dokumen (metadata) yang dapat diakses full-text-nya.

Tujuan penelitian ini untuk mendeskripsikan sejauh mana tingkat efektifitas, efisiensi, kemudahan dipelajari, dan kemampuan untuk berinteraksi tanpa kesulitan atau kesalahan dari antarmuka (user interface) MM-Digilib serta ketergunaan yang telah dicapai MM-Digilib di Perpustakaan MM-FEUI.

\section{TINJAUAN PUSTAKA}

\section{Perpustakaan Perguruan Tinggi}

Perpustakaan memiliki dasar hukum yang tertuang dalam beberapa Peraturan Pemerintah. Peraturan Pemerintah Nomor 30 tahun 1990 tentang Pendidikan Tinggi, pembahasan mengenai perpustakaan dimuat dalam Pasal 27 Butir 7 angka 10; Pasal 34 Ayat 2; Pasal 55 Ayat 1; Pasal 69 Ayat 1; Pasal 82 Ayat 1; Pasal 95 Ayat 1 mengatakan bahwa perpustakaan ialah unsur penunjang yang perlu ada pada semua bentuk perguruan tinggi, mulai dari universitas, institut, sekolah tinggi, politeknik dan akademi (Septiyantono, 2003:11).

Perpustakaan perguruan tinggi berfungsi untuk menyediakan informasi yang diperlukan oleh lembaga induknya untuk mendukung kegiatan riset dan akademik (Nera, 1993:2). Kualitas pendidikan di lembaga tinggi bergantung antara lain pada kemampuan perpustakaannya (Roesma, 1992:1). Sementara itu Fowler mengatakan bahwa perpustakaan adalah institusi pembelajaran yang melahirkan inovasi. Oleh karena itu, perpustakaan haruslah bersifat proaktif dengan terus meningkatkan kualitas dan efisiensinya karena tantangan pada tingkat perguruan tinggi adalah kompetensi (Fowler, 1998:23). Bahkan Hardesty mengatakan bahwa perpustakaan merupakan jantung universitas. Semua universitas yang bereputasi tinggi biasanya memiliki investasi sumberdaya pengetahuan yang tinggi (Hardesty, 1991:1). Berdasarkan pendapat-pendapat di atas dapat disimpulkan bahwa perpustakaan perguruan tinggi selain harus menyediakan sarana pendukung kegiatan riset dan akademik, juga harus meningkatkan mutu layanannya sebagai bentuk investasi jangka panjang dunia pendidikan.

\section{Pengertian Perpustakaan Digital}

Putu L. Pendit (2005 :11) mengatakan bahwa perpustakaan digital tidak dapat diterjemahkan secara kaku dalam arti suatu perpustakaan tidak memiliki koleksi tercetak sama sekali. Namun, koleksi tersebut dilayankan dalam format elektronik/virtual/digital dan dapat diakses oleh jaringan informasi. Hal ini sesuai dengan yang disampaikan oleh National Science foundation tentang tiga karakteristik utama perpustakaan digital, antara lain, pertama, memakai teknologi yang mengintegrasikan kemampuan menciptakan, mencari, dan menggunakan informasi dalam berbagai bentuk didalam sebuah jaringan digital yang tersebar luas. Kedua, memiliki koleksi yang mencakup data dan metadata yang saling mengaitkan data, baik di lingkungan internal maupun eksternal. Ketiga, merupakan kegiatan mengoleksi dan mengatur sumberdaya digital yang dikembangkan bersama-sama komunitas pemakai jasa untuk memenuhi kebutuhan informasi komunitas tersebut. Komunitas pemakai jasa informasi secara khusus adalah pengguna perpustakaan MM-Digilib dan pengelola perpustakaan MM-Digilib.

Kenyataan di lapangan menunjukkan pepustakaan digital merupakan perluasan logis dari dimensi fungsi dan peran perpustakaan pada umumnya. Perpustakaan "konvensional" diukur berdasarkan jumlah koleksi sedangkan perpustakaan digital sebagai perpanjangan fungsi Perpustakaan "konvensional" memberikan nilai yang tidak hanya berdasarkan koleksi tetapi juga karena adanya cakupan jaringan informasi yang dibentuk dan jasa yang dapat diberikan. Sehingga suatu organisasi dapat menyatakan diri sebagai perpustakaan digital apabila dapat menyediakan "a single point of access" ke serangkaian sumberdaya yang tersebar secara otonom (Paepcke et al, 1996: 61-68). Menurut hemat penulis, "a single point of access" yang dimaksud adalah jaringan itu sendiri. Baik jaringan 
internal maupun global. Meskipun pada dasarnya setiap perpustakaan hibrid dan digital menggunakan teknologi berbasis web, namun mau tidak mau tetap harus terhubung dengan jaringan internal. Beberapa perpustakaan yang mengusung konsep perpustakaan digital ditemukan bahwa sistem layanan (penelusuran/OPAC) tidak terintegrasi dengan kegiatan operasional (pengolahan, pengadaan, sirkulasi). Kebanyakan perpustakaan di Indonesia berjenis perpustakan hibrida.

\section{Uji Ketergunaan antarmuka MM-Digilib}

Tampilan sistem yang simple, menarik, informatif dan mudah dipelajari akan memberikan efektifitas dalam penggunaan sistem. Sedangkan tampilan yang membingungkan akan membuat pengguna merasa sulit menggunakannya dan cenderung untuk tidak memakai sistem tersebut (Armstrong, Chris dan Andrew Large, 1997: 13). Michelle dan Wang (dalam Chowdhury, 2003:69) mengemukakan pentingnya antarmuka berbasis pemakai bagi pengguna perpustakaan digital yang heterogen.

Ketergunaan sendiri merupakan suatu disiplin yang menerapkan observasi ilmiah, terukur serta memiliki prinsip-prinsip desain untuk menciptakan dan memelihara sebuah situs dalam rangka membawanya kepada kemudahan penggunaan, kemudahan dipelajari, banyak kegunaannya (usefullness), dan sedikit ketidaknyamanan bagi pengguna yang menggunakan sistem. Atribut dari ketergunaan yang didefinisikan oleh para ahli dapat dilihat pada tabel 1 .

Ketergunaan dilihat dari segi efisiensi (baik efisiensi secara internal maupun eksternal), segi kemudahan mempelajari (melalui bahasa, tampilan antarmuka MM-Digilib), segi kemampuan untuk berinteraksi tanpa kesulitan dan kesalahan (login dan strategi penelusuran pengguna), segi efektifitas (kemampuan sistem navigasi, kesesuaian, keakuratan, konsistensi, kemampuan memacu kreativitas \& inisiatif pengguna, frekuensi penggunaan, rata-rata lama penggunaan, serta indikator yang mengukur kepuasan yakni kenyamanan dan pendapat subyektif pengguna tentang tingkat penerimaan terhadap antarmuka MM-Digilib).

\section{METODE PENELITIAN}

Penelitian deskriptif berkaitan dengan pengumpulan fakta, identifikasi dan meramalkan hubungan dalam dan antara variabel (Sulistyo Basuki, 2006 :111). Pendekatan yang digunakan adalah pendekatan kuantitatif dengan metode survei dan alat pengumpulan data berupa kuisioner.

Subjek penelitian adalah mahasiswa S2 yang menggunakan layanan antarmuka MM-Digilib di Perpustakaan MM-FEUI. Sedangkan objek penelitian adalah antarmuka pengguna (user interface) MM-Digilib. Untuk populasi atau keseluruhan objek yang diteliti (Sulistyo-Basuki, 2006: 182) meliputi mahasiswa S2 yang menggunakan layanan tesis digital di Perpustakaan MM-FEUI. Besarnya sampel atau bagian tertentu dari keseluruhan objek, diambil berdasarkan rumus Slovin dan faktor pemilihan yang digunakan adalah pertimbangan ini merupakan pendapat ahli Singarimbun.

Tabel 1. Atribut Ketergunaan

\begin{tabular}{ll}
\hline \multicolumn{1}{c}{ Author } & \\
\hline $\begin{array}{l}\text { The International Standard } \\
\text { Organization (1994:10) }\end{array}$ & Effectiveness, Efficiency, Satisfaction \\
$\begin{array}{l}\text { Nielsen (1993) } \\
\text { Brinck, Gergle, }\end{array}$ & Learnability, Efficiency, Memorability, Low error Rate / Easy Error Recovery, Satisfaction \\
and Wood (2002) & Fuctionally Correct, Efficient to Use, Easy to Learn \& Remember, Error Tolerant, \\
Booth (1989) & Subjectively Pleasing \\
Hix dan Hartson & Usefulness, Effectiveness (ease of use), Learnability, and attitude (likeability) \\
(1993) & Initial performance, Long term Performance, Learnability, Retainability, Advanced \\
Kengeri et al. (1999) & Effectiveness, Likeability, Learnability, Usefulness \\
Kim (2002) & Interface Effectiveness \\
Oulanov \& & Affect, Efficiency, Control, \\
Pajarillo (2002) & Helpfulness, Adaptability \\
Shackel (1986) & Effectiveness, Learnability, Flexibility, User Attitude
\end{tabular}


Author Atribut

Guillemotte (1995) Effectivelly used by target users to perform task

Dumas and Redish (1993) Perform task quickly and easily

Furtado et.al Efficiency, ease of learning, and the ability to remember how to peform interactive task

Badre (2002) without difficulity or errors.

Berdasarkan rumus Slovin dan Nomogram Herry King didapat 87 sampel dari 651 ukuran populasi dan taraf kesalahan 5\%. Dari 87 sampel terdapat 6 yang dianggap tidak valid. Sehingga tersisa 81 sampel yang diberikan survei kuesioner.

\section{HASIL DAN PEMBAHASAN}

Berdasarkan indikator-indikator ketergunaan antarmuka (user interface) MM-Digilib dilakukan survei kuesioner kepada 81 responden yang meliputi:

\section{Segi Efisiensi}

Suatu sistem dinilai efisien apabila meningkatkan produktifitas penggunanya. Efisiensi secara internal adalah dapat mengganti tugas - tugas manual, meningkatkan kualitas dan kuantitas pencarian, mempercepat penelusuran dan memberikan siklus penyebaran informasi. (ISO 9241 bagian 11).

Hasil yang diperoleh menunjukkan responden sebanyak 54,3\% dari 81 responden menilai bahwa antarmuka (user interface) MM-Digilib efektif memfasilitasi kebutuhan sosial keilmiahan terutama mengakomodasi kebutuhan responden akan publikasi karya ilmiah. Hal ini sudah mencakup semua kriteria efisiensi internal.

Segi efisiensi terlihat dari salah satunya dari efisiensi yang didapat dari fasilitas Login pengguna. Fasilitas yang hanya perlu memasukkan user-id dan password sebagai pintu gerbang memasuki suatu sistem. Ternyata ditemukan bahwa sebagian besar responden melakukan Login yakni $86,4 \%$. Alasannya adalah karena responden hendak mengakses Thesis Digital. Responden yang tidak melakukan Login juga dapat dengan mudah menelusur untuk mengetahui keberadaan koleksi dan nomor panggilnya.

Peneliti menganggap Login ini penting karena dapat meningkatkan kualitas dan kuantitas pencarian bagi pengguna berupa adanya akses ke pengunduhan berkas dan fasilitas lain. Pengguna yang tidak melakukan Login hanya dapat mengetahui judul dan nomor panggil koleksi perpustakaan. Hal ini mempengaruhi hasil penelusuran dan memberikan kontribusi pada siklus penyebaran informasi. Hasil terlihat pada Tabel 2.
Tabel 2

Login Pengguna MM-Digilib

\begin{tabular}{ccc}
\hline Login & Frekuensi & Persentase \\
\hline Ya & 70 & 86.4 \\
Tidak & 11 & 13.6 \\
Total & 81 & 100 \\
\hline
\end{tabular}

\section{Kemudahan Mempelajari}

Bahasa yang digunakan mempengaruhi interpretasi pengguna terhadap hasil penelusuran. Bahkan bahasa mempengaruhi ketergunaan menurut Gould (1988). Namun, bagi responden, penggunaan Bahasa Indonesia dan Bahasa Inggris memiliki perbedaan yang tidak signifikan mengingat latar belakang pendidikan yang cukup tinggi sehingga tidak memiliki hambatan dalam penggunanaan kedua bahasa. Alasan lainnya adalah karena mahasiswa S2 terbiasa dengan Bahasa Inggris.

Hasil dari data yang diperoleh menunjukkan bahwa antarmuka (user interface) $\mathrm{MM}$ - Digilib mudah dipelajari dari segi bahasa karena menyediakan dua bahasa yang familiar dengan responden yakni Bahasa Inggris dan Indonesia (63\% responden). Bahasa yang lebih banyak digunakan responden adalah Bahasa Inggris, sebanyak 23,5\% menggunakannya untuk penelusuran. Hanya sedikit responden yang menggunakan Bahasa Indonesia yakni $13,6 \%$, terlihat di tabel 3 .

Tabel 3

Bahasa Penelusuran

\begin{tabular}{lrr}
\hline \multicolumn{1}{c}{ Bahasa Penelusuran } & Frekuensi & Persentase \\
\hline Bahasa Indonesia & 11 & 13.6 \\
Bahasa Inggris & 19 & 23.5 \\
Keduanya Baik & 51 & 63 \\
Total & 81 & 100 \\
\hline
\end{tabular}

Tampilan antarmuka merupakan jembatan antara pengguna dan sistem maupun ke koleksi digital. Kemudian dari segi tampilan antarmuka (user interface) MM - Digilib memiliki desain arsitektur yang simpel, menarik dan informatif sehingga responden merasa Cukup mudah mempelajari, terlihat pada tabel 4. 
Tabel 4

Tampilan antarmuka (user interface) MM - Digilib

\begin{tabular}{lrr}
\hline Penilaian Tampilan & Frekuensi & Persentase \\
\hline Sangat Bagus & 9 & 11,1 \\
Bagus & 25 & 30.9 \\
Cukup Bagus & 33 & 40.7 \\
Kurang Bagus & 13 & 16 \\
Total & 80 & 98.8 \\
Tidak Menjawab & 1 & 100 \\
\hline
\end{tabular}

\section{Kemampuan Berinteraksi}

Kemampuan berinteraksi dapat diukur dari seberapa besar tingkat kesulitan dan kemudahan responden mencari informasi pada antarmuka (user interface) MM- Digilib. Sebanyak 40,7\% menyatakan bahwa antarmuka (user interface) MM-Digilib Mudah digunakan, 34,6\% lainnya mengatakan cukup mudah digunakan. Sehingga dapat disimpulkan bahwa antarmuka (user interface) MM-Digilib secara umum mudah digunakan oleh sebagian besar responden. Alasan responden adalah karena kelengkapan menu dan navigasi. Meskipun tingkat kesulitan dan kemudahan ini juga dipengaruhi oleh keterampilan pengguna (Dix, Finlay, Ábowd, dan Beale(1992:162-175), terlihat pada tabel 5

Tabel 5

Tingkat Kesulitan dan Kemudahan pada Antarmuka (user interface) $\mathrm{MM}$ - Digilib

\begin{tabular}{lrr}
\hline $\begin{array}{c}\text { Tingkat Kesulitan } \\
\text { dan Kemudahan }\end{array}$ & Frekuensi & Persentase \\
\hline Sangat Mudah & 17 & 21 \\
Mudah & 33 & 40.7 \\
Cukup & 28 & 34.6 \\
Sulit & 3 & 3.7 \\
Total & 81 & 100 \\
\hline
\end{tabular}

Berkaitan dengan alasan responden diatas, peneliti juga mencari tahu tentang Kemampuan Sistem Navigasi pada antarmuka (user interface) MM-Digilib menurut responden. Sebanyak 43,5\% menyatakan Baik dan hanya berbeda sedikit dengan yang mengatakan Sangat Baik yakni 35,5\%, terlihat pada tabel 6.

Tabel 6

Kemampuan Sistem Navigasi Antarmuka (user interface) $\mathrm{MM}-$ Digilib

\begin{tabular}{lrr}
\hline $\begin{array}{c}\text { Kemampuan Sistem } \\
\text { Navigasi }\end{array}$ & Frekuensi & Persentase \\
\hline Sangat Baik & 29 & 35.8 \\
Baik & 35 & 43.2 \\
Cukup Baik & 15 & 18.5 \\
Kurang Baik & 2 & 2.5 \\
\hline
\end{tabular}

Responden juga lebih banyak menggunakan pilihan penelusuran Simple Search yakni 70,4\% dibanding dengan sisanya yang menggunakan Advanced Search.

Tabel 7

Cara penelusuran

\begin{tabular}{lrr}
\hline Pilihan Penelusuran & Frekuensi & Persentase \\
\hline Simple Search & 57 & 70.4 \\
Advance Search & 24 & 29.6 \\
Total & 81 & 100 \\
\hline
\end{tabular}

Pengguna Simple Search ini menganggap penggunaan Advanced Search lebih banyak menghabiskan waktu. Padahal Advanced Search berfungsi meningkatkan ketepatan dan kemampuan pengguna berinteraksi dengan sistem.Lebih lanjut dipastikan apakah responden pernah menggunakan Advanced Search, ditemukan bahwa sebagian besar responden $61,7 \%$ pernah menggunakannya.

Tabel 8

Penggunaan Advanced Search

\begin{tabular}{lrr}
\hline Jawaban Responden & Frekuensi & Persentase \\
\hline Pernah & 50 & 61.7 \\
Tidak Pernah & 31 & 38.3 \\
Total & 81 & 100 \\
\hline
\end{tabular}

Pola umum kegiatan sebagaimana dikatakan Witherington berbunyi: "individu merasakan adanya suatu kebutuhan, kemudian individu bertindak untuk memenuhi kebutuhan itu." (Witherington, 1963 :57). Individu atau pengguna digerakkan oleh alasan atau motif. Alasan responden menggunakan Advanced Search antara lain karena, pertama, memerlukan informasi yang tepat. Kedua, karena ketidakpuasan terhadap Simple Search.

Kedua hasil survei pada Tabel 7 dan Tabel 8 diatas menunjukkan bahwa para pengguna yang telah berinteraksi dengan Advanced Search merasa waktunya berinteraksi dengan sistem jadi lebih banyak sehingga untuk mendapat informasi cepat dan tidak dalam maka mereka menggunakan Simple Search.

\section{Segi Efektifitas}

Selain menunjukkan Tingkat Kemampuan Berinteraksi, penilaian akan Sistem Navigasi (Tabel 6) juga mendukung Segi Efektifitas. Hasil yang diperoleh berdasarkan kriteria evaluasi efektifitasyakni kepuasan pemakaidan lama rata-rata pemakaian menunjukkan bahwa dari segi kepuasan, antarmuka (user interface) MM-Digilib memiliki responden terbanyak memberikan 
komentar bahwa sistem navigasi antarmuka (user interface) MM-Digilib sudah Baik yakni $43,2 \%$. $\mathrm{Hal}$ lain yang menjadi gambaran kepuasan responden adalah segi Kesesuaian antara Hasil Pencarian (recall) dan Kesesuaian / Ketepatan (presicion). Responden terbanyak yakni $42 \%$ menyatakan antarmuka (user interface) MM-Digilib telah Sesuai dalam hasil pencarian dan tingkat kesesuaian/ketepatan, terlihat pada tabel 9.

Tabel 9

Kesesuaian antara Hasil Pencarian dan Keinginan

\begin{tabular}{lrr}
\hline $\begin{array}{c}\text { Jawaban } \\
\text { Responden }\end{array}$ & Frekuensi & Persentase \\
\hline Sangat Sesuai & 19 & 23.5 \\
Sesuai & 34 & 42 \\
Cukup Sesuai & 26 & 32.1 \\
Kurang Sesuai & 2 & 2.5 \\
Total & 81 & 100 \\
\hline
\end{tabular}

Berkaitan dengan Konsistensi sistem,79\% responden menyatakan bahwa antarmuka (user interface) MM-Digilib konsisten: Bahkan 14,8\% respondeǹ menyatakan bahwa sistem Sangat Konsisten. Sehingga dapat disimpulkan bahwa sistem ini telah stabil, terlihat pada Tabel 10 ,

Tabel 10

Konsistensi Hasil Pencarian

\begin{tabular}{lrr}
\hline \multicolumn{1}{c}{ Jawaban } & Frekuensi & Persentase \\
\hline Sangat Konsisten & 12 & 14.8 \\
Konsisten & 64 & 79 \\
Kurang Konsisten & 5 & 6.2 \\
Total & 81 & 100 \\
\hline
\end{tabular}

Berkaitan dengan lama rata-rata penggunaan antarmuka (user interface) MM - Digilib, responden terbanyak yakni 49,4\% mengatakan bahwa rata-rata lama waktu yang mereka gunakan adalah 31-60 menit, tidak terpaut jauh dari responden yang menyatakan penggunaan waktu yang dihabiskan untuk berinteraksi dengan antarmuka (user interface) MM-Digilib hanya dibawah 30 menit yakni $45,7 \%$.Hal ini menunjukkan hasil yang kurang menggembirakan, dimana rata-rata lama waktu pemakaian mendekati bahkan melebihi 30 menit. Berdasarkansegi efektifitas, hal ini merupakan salah satu indikasi bahwa ada hal yang perlu ditingkatkan untuk mempercepat penelusuran, terlihat pada Tabel 11.
Tabel 11

Rata - rata Lama Penggunaan MM-Digilib

\begin{tabular}{lcc}
\hline \multicolumn{1}{c}{ Waktu } & Frekuensi & Persentase \\
\hline Kurang dari 30 menit & 37 & 45.7 \\
31-60 menit & 40 & 49.4 \\
Tidak pernah menghitung & 4 & 4.9 \\
Total & 81 & 100 \\
\hline
\end{tabular}

\section{KESIMPULAN}

1. Berdasarkan segi efisiensi internal, antarmuka (user interface) MM-Digilib memilikikemudahan dalam akses ke sistemnya melalui fasilitas Login yang memudahkan mendapatkan informasi secara lebih lengkap serta secara umum antarmuka (user interface) MM-Digilib telah membantu memenuhi kebutuhan pengguna (responden Mahasiswa S2 MM-FEUI) dalam mendapatkan publikasi karya ilmiah.

2. Berdasarkan segi Kemampuan Berinteraksi, sebagian besar responden mengatakan antarmuka (user interface) MM-Digilib Cukup Mudah dan Mudah digunakan. Namun, sayangnya fasilitas penelusuran dengan Advanced Search masih belum banyak digunakan karena membutuhkan waktu yang lebih lama dalam mencari informasi di bandingkan penelusuran dengan Simple Search.

3. Berdasarkan segi efektifitas, sebagian besar responden menilai bahwa antarmuka (user interface) MM-Digilib menyatakan bahwa hasil penelusuran mereka telah konsisten, sesuai dan tepat. Namun, sayangnya pengguna masih memerlukan waktu lebih banyak dalam menemukan informasi yang mereka perlukan. Hal ini dinilai kurang baik dari segi efektifitas.

\section{SARAN}

1. Tampilan antarmuka (user interface) MMDigilib untuk penelusuran khusus Advanced Search sebaiknya dimodifikasi lagi agar pengguna lebih mudah menggunakan dan mempersingkat proses penemukembalian (retrieval) data.

2. Perlu peningkatan lagi secara lebih menyeluruh dari tampilan antarmuka (user interface) MM Digilib agar lebih menarik pengunjung dari luar lembaga. 


\section{DAFTAR PUSTAKA}

Badre, A.N. Shaping Web Usability : Interaction Design in Context. Boston : Addison - Wesley, 2002.

Basuki, Sulistyo. Metode Penelitian. Jakarta : Wedatama Widya Sastra, 2006.

Chowdhurry, G.G. Introduction to Digital Libraries. London. Facet Publishing, 2003.

Dix, A.J., Finlay, G.D Abowd J.E. dan R. Beale. Human - Computer Interactions. Ed. Kedua. Harlow, England: Prentice Hall, 1992.

Dumas, JosephS., dan Janice C. Redish. A Practical Usability Testing. Norwood, N..J. : Ablex, 1993.

Guillemette, Ronald A. "The Evaluation of Usability in Interactive Information System" dalam Human Factors in Information Systems: Emerging theoritical bases, ed. Jane M. Carey. Norrwood, N.J. : Ablex, 1995.

Hardesty, Larry. Why Do We Need Academic Libraries?http://www.ala.org/acrl/ academiclib.html(Juni 2007), 1991
Kengeri, Rekha, et al. Usability Study of Digital Libraries : ACM, IEEE-CS, NCTRL, NDLTD. International Journal on Digital Libraries $2: 157$ $-69,1999$.

Paepcke, A., et al. Using Distributed Objects for Digital Library Interoperability. Computer 29 (5) : 61-68, 1996.

Nera, Corazon M. Introduction to ASEAN Librarianship : Academic Libraries. Jakarta : The Asean Committe on Culture and Information, 1993.

Roesma, Lily I. "Promosi Jasa Perpustakaan Perguruan Tinggi", makalah pada KPP Pusdokinfo, Depok, 3-6 Februari 1992

Singarimbun, Masri, dan Effendi, Sofian. Metode Penelitian Survai. Yogyakarta :LP3ES, 1989.

Sugianti, Sri. Uji Ketergunaan Layanan Antarmuka Magister Management Digital Library (MMDigilib) Perpustakaan Magister Manajemen FEUI. Skripsi Ilmu Perpustakaan dan Informasi Universitas Indonesia, Depok, 2007. 